https://doi.org/10.31470/2706-7904-2021-16-205-212

\title{
PROCESSING EMOTION WORDS IN THE LATE-LEARNED L2
}

Обробка слів-емоцій при пізньому вивченні L2

\author{
Filiz Mergen \\ Ph.D. in Linguistics, Assistant Professor \\ University of Economics, Izmir (Turkey) \\ filiz.mergen@ieu.edu.tr \\ https://orcid.org.0000-0002-9583-9153 \\ Gulmira Kuruoglu \\ Ph.D. in Linguistics, Professor \\ Dokuz Eylul University, İzmir (Turkey) \\ gulmira.kuruoglu@deu.edu.tr \\ https://orcid.org/0000-0002-4172-0253
}

\begin{abstract}
Language-emotion link has been a subject of interest for several decades. It has been studied extensively both in the monolingual and bilingual literature. However, due to the numerous factors that are at play in bilingualism, i.e. age and context of acquisition, frequency of use, there is conflicting evidence regarding the emotional load of each language of bilinguals. A great bulk of evidence leans towards the L1 as the more emotional language. This study investigates the perceived emotionality in the late learned language. Our participants $(N=57)$ were late bilinguals who learned their second language (English) in formal contexts after their first language (Turkish). We used a lexical decision task in which the participants determined whether the visually presented emotion words were real words or non-words. In line with the literature, we report faster response times for positive than for negative words in both languages. Also, the results showed L1 superiority in word processing.
\end{abstract}

Key words: late bilinguals, emotion words, psycholinguistics.

\section{Introduction}

Bcmyn

Bilingualism is influenced by a variety of factors such as age of acquisition (AoA) of the languages, context of learning, frequency of use of each language. However, the dynamic nature of bilingualism makes it hard to categorize bilinguals. For example, no consensus has been reached regarding the age cut-off for age of acquisition. A great bulk of evidence has shown that it is around age 5 when language components such as phonology 
and syntax are resistant to maturational changes in the brain (Paradis, 2004). Emotion research in the bilingual literature, however, has shown that emotional content of language is also vulnerable to age affects, particularly when the second language is learnt through formal education (Caldwell-Harris, Sanches \& Nayaka, 2014; Chen, Lin, Chen, Lu \& Guo, 2015; Ong, Hussein, Chow \& Thompson, 2017). However, it is maintained that proficiency level or length and amount of exposure may compensate for the age and context of acquisition effects (Grabitz, Watkins \& Bishop, 2016; Kazanas \& Altarriba, 2016; Ong, Hussain, Chow \& Thompson, 2017).

It is well-established in the literature that emotional stimuli have a privileged status in the brain as it relates to our survival (Vinson, Ponari \& Vigliocco, 2014; Knickerbocker, Johnson and Altarriba, 2015). However, there is dissension over the nature of this privilege. One line of reseach holds that positive, but not negative words show a processing advantage (Briesemeister, Kuchinke \& Jacobs, 2011; Kissler et al., 2009; Kissler \& Koessler, 2011; Palazova et al., 2011) while another line of research argues that emotions, regardless of valence have priority in lexical processing (Kousta, Vinson \& Vigliocco, 2009). The former view is known as Positivity Bias, according to which positive stimuli are advantageous for us, enhancing happiness and well-being while negative stimuli require detailed processing as it might be potentially threatening (Estes \& Adelman, 2008).

In the bilingual literature, interrelation between emotions and language has been the subject of many studies. The results have been interpreted with regard to the emotional load of each language of bilinguals. It is known that the first learned language is more emotional (Dewaele, 2004a, 2004b; Pavlenko, 2004; Kim \& Starks, 2008; Winskel, 2013; Hsu, Jacobs \& Conrad, 2015; Toivo \& Scheepers, 2019). Reasearch has shown that when a language is learned later, especially in formal settings, it is less emotional. Some views have been put forward to explain this. One such view is that the first language acquisition is supported by the early maturing emotion network in the brain (Pavlenko, 2012). Studies conducted with healthy subjects (Dewaele, 2004a, 2004b; Pavlenko, 2004; Kim \& Starks, 2008) as well as those with theraupatic cases (Freud, 1893 cited in Pavlenko, 2012) and psychophysiological studies support this view (Harris, 2004; Caldwell-Harris, Sanchez \& Nayaka, 2014). However, it is maintained that proficiency (Ong, Hussain, Chow \& Thompson, 2017) and frequency of use of the languages (Kazanas \&Altarriba, 2016) may affect the extent of perceived emotionality in L2.

\section{Participants}

57 late bilinguals (22 males, 35 females), whose native language is Turkish, and who learned English as a foreign language through formal schooling took part in the study. They were translation trainees at a private university in Izmir. They completed a preparatory program and all deemed themselves as proficient speakers of L2. Before the study, they were asked to fill out a questionnaire adapted from Common European Framework for 
Languages. We found no significant difference among L2 proficiency levels of the participants (all $p \mathrm{~s}>.05$ ). They were given no course credit or participation fee. The Ethical Committee of the university gave approval for the study.

Table 1.

Demographic information and language background

\begin{tabular}{ll}
\hline & Mean \\
\hline Age & 18.93 \\
\hline Age of L2 Acquisition & 9.95 \\
\hline Self-reported proficiency & \\
\hline Listening & 3.49 \\
\hline Speaking & 3.71 \\
\hline Reading & 4.60 \\
\hline Writing & 4.03 \\
\hline
\end{tabular}

\section{Stimuli}

The stimuli consisted of two word sets, which were used in a previous study on emotion word processing in simultaneous bilinguals (Mergen \& Kuruoglu, 2018). In the Turkish word set, we used 10 positive and 10 negative words selected from a pool of 300 words (Göz, 2003). A hundred native speakers of Turkish rated them according to valence (i.e.positive and negative). An ANOVA was conducted on the data, and the results showed significant difference in valence, $F(2,27)=98.01, p<.001, \mathrm{y}^{2}=.879$, while we found no significant difference in frequency, $F(2,27)=0.83, p>.05, \mathrm{y}^{2}=.058$. To form the English word set, we selected 300 words from Affective Norms for English Words (Bradley and Lang, 1999), and used a total of 10 positive and 10 negative words out of this pool, based on the ratings of 30 native speakers of English. As revealed by ANOVA, a significant difference was found in valence, $F(2,27)=1183.11, p=.000, \mathrm{y}^{2}=.989$, but not in frequency, $F(2,27)=0.46, p=.638, \mathrm{y}^{2}=.033$. Non-words were formed in each word set, considering the phonotactics of each language.

\section{Procedure}

The current study aims to investigate L2 emotion word processing in both languages of late bilinguals. Our participants performed a lexical decision task. The experiment was conducted in a quiet, dimly-lit room, with one participant at a time. To familiarize the participants with the procedure before the experiment, they were given a test trial with 10 words in each language. They were seated in front of a laptop computer at a distance of 40 $\mathrm{cm}$ during the whole experiment. The stimuli were presented for $200 \mathrm{~ms}$. on the screen in a random order, and ISI was 1000 ms. Finally, a mask was seen on the screen until the next trial started. Language blocks were counterbalanced across participants. They were told to press the designated keys on the keyboard to indicate whether they considered the letter 
strings to be real words or non-words. They were reminded to be as fast and accurate as possible. Their response times and the accuracy of their answers were recorded via SuperLab 4.0 software and the SPSS 18.0 was performed to analyse the data.

\section{Results \\ Результати}

Mean RTs were calculated for accurate responses. For each participant, response times shorter than $300 \mathrm{~ms}$ and longer than $1500 \mathrm{~ms}$ were removed. A paired samples $t$-test was conducted on the data.

\section{Table 2}

Bilinguals' response times to Turkish and English emotion words

\begin{tabular}{lllll}
\hline & $\begin{array}{l}\text { Positive Words } \\
(\mathbf{m s})\end{array}$ & $\begin{array}{l}\text { Standard } \\
\text { Deviation }\end{array}$ & $\begin{array}{l}\text { Negative Words } \\
(\mathbf{m s})\end{array}$ & Standard Deviation \\
\hline Turkish & 511.35 & 106.88 & 539.73 & 110.47 \\
\hline English & 549.95 & 115.82 & 613.14 & 141.91 \\
\hline
\end{tabular}

The results showed that positive words $(M=530.65, S D=101.49)$ in both languages were processed faster than negative words $(M=576.44, S D=107.92)$. The difference was found significant, $t(56)=-4.43, p=.001$. Language-wise comparisons showed a significant L1 superiority in both emotion word types (Positive words: $t(56)=3.17, p=.003$; Negative words: $t(56)=4.12, p=.000)$.

\section{Discussion Дискусії}

In the current study, we investigated the processing of emotion words in the two languages of late bilinguals. Our participants performed a lexical decision task. Our results support widely accepted views in the literature.

Firstly, we provide further support for the privileged status of positive words as compared to negative words. Our participants responded to positive words faster than negative words in both languages. The literature abounds with evidence that positive stimuli enjoys a processing advantage in the brain (Kissler \& Koessler, 2011; Briesemeister, Kuchinke \& Jacobs, 2011; Palazova et al., 2011). As suggested by Positivity Bias, positive stimuli is prioritized as it enhances happiness and well-being. As for the processing of negative words, we replicate the well-established finding that negative information slows down processingand increases participants' response times as it might involve threat for the organism (Estes \& Adelman, 2008). Also, due to less frequent appearance of negative stimuli as compared to positive stimuli, novelty effect may account for the delays in 
processing negative information (Larsen, Kimberley, Mercer \& Balota, 2006). Similar results were reported in the bilingual literature (Kazanas \& Altarriba, 2016).

Secondly, we compared processing of emotion words in both languages of late bilinguals. The results showed that our participants responded faster to emotion words in their L1 than those in L2. The implication of this result is two-fold. First, it can be interpreted as L1 superiority in lexical processing as both positive and negative words elicited faster response times in L1. According to Bilingual Interactive Activation Model (Dijkstra and \& Heuven, 2002), frequency of use of languages predicts easier access by facilitating their selection during processing. Late bilinguals in our study responded faster to L1 words because they use their L1 as a means of communication on a daily basis. Their L2, on the other hand, is used in the school context, thus being less frequent as compared to L1. Similar results were reported by Gollan et al. (2008). De Bruin, Sala and Bak (2016) provided support for the role of frequency of language use based on a comparison of two groups of bilinguals. Faust, Ben-Artzi and Vardi (2012) associated faster processing in L1 to a fuller and richer representations of L1 words in the semantic network as compared to those in the late-learned language. Lehtonen et al. (2012) argued that frequency effects are more pronounced in bilinguals than in monolinguals because the former deals with more words in the lexicon during the retrieval process. All in all, our results support the view that frequency of use of one of the two languages of bilinguals may lead to faster processing in that language.

The second implication of our results may be associated with reduced emotionality in L2. Because our participants needed less time to process emotion words in their L1, it can be said that they are more sensitive to the emotional content of L1 words. The view that L1 is more emotional than the language(s) learned later in life has been widely supported in the bilingual literature (Dewaele, 2004a, 2004b; Pavlenko, 2004; Harris, 2004; Opitz \& Degner, 2012). Reduced emotionality in the late-learned L2, particularly when it comes through formal instruction, has been associated with lack of opportunity to use it in authentic interactions. Winskel (2013) argued that late bilinguals are not able to access emotional connotations of L2 words as readily as in L1. In Segalowitz et al. (2008) study, longer latencies for emotion word recognition in L2 as compared to L1 were reported. Jonczyk et al. (2016) reported that Polish-English bilinguals had longer response times for positive and negative words in their L2 than in L1, although the words were presented in sentential context, which is considered to facilitate processing. Similarly, imaging studies (Hsu, Jacobs \& Conrad, 2015) and psychophysiological studies (Caldwell-Harris, Sanchez \& Nayaka, 2014) lend further support to L1 superiority in emotional load for late bilinguals. It can be said that our results replicate the findings in the literature. 


\section{Conclusion}

Висновки

It has been well-established in the literature that bilinguals differ from monolinguals in word processing as they monitor two languages during processing. Emotional content of word influences this process in various ways, particularly when one of the languages is learned later in formal contexts. In this study, we aimed to investigate how emotion words in both languages of late bilinguals are processed. Our participants performed a lexical decision task in which they determined whether the words in each language were real words and non-words. We found that positive words were processed faster than negative words in each language, providing further evidence regarding the privileged status of positive words in processing. Secondly, our participants performed better in processing L1 words than L2 words regardless of valence. This result suggests L1 superiority in word processing. This result may also be interpreted as reduced sensitivity to the emotional content of L2 words. All in all, our results are in line with the overwhelming evidence in the literature regarding bilingual word processing.

\section{References}

Jimepamypa

Bradley, M.M., \& Lang, P.J. (1999). Affective Norms for English Words. Instruction Manual and Affective Ratings. Available at: http://www.uvm.edu/ pdodds/files/papers/others/1999/bradley1999a.pdf (accessed 1 Feb 2010)

Briesemeister, B.B., Kuchinke, L., \& Jacobs A.M. (2011). Discrete emotion effects on lexical decision response times. PlosONE, 6(8), 1-9. https://doi.org/10.1371/journal.pone.0023743

Caldwell-Harris, C.L., Sanches, N., \& Nayaka, N. (2014). When early and late bilinguals lie: skin conductance responses during a deception task. Boston University Psycholinguistics Laboratory Working Avaliable at: https://bu.academia.edu/CatherineCaldwellHarris/Papers (accessed 10 June 2017).

Chen, P., Lin, J., Chen, B., Lu, C., \& Guo, T. (2015). Processing emotional words in two languages with one brain: ERP and fMRI evidence from Chinese-English bilinguals. Cortex, 71, 3448. https://doi.org/10.1016/j.cortex.2015.06.002

De Bruin, A., Sala, S.D., \& Bak, T.H. (2016). The effects of language use on lexical processing in bilinguals. Language, Cognition and Neuroscience, 31(8), 967-974. https://doi.org/10.1080/23273798.2016.1190024

Dewaele, J.M. (2004a). The emotional force of swear words and taboo words in the speech of multilinguals. Journal of Multilingualism and Multicultural Development, 25(2-3), 204222. https://doi.org/10.1080/01434630408666529

Dewaele, J.M. (2004b). Blistering barnacles! What languages do multilinguals swear in? Estudios de Sociolinguistica, 5(1), 83-105. https://doi.org/10.1558/sols.v5i1.83 
Dijkstra, T., \& van Heuven, W.T.B. (2002). The architecture of the bilingual word recognition system: from identification to decision. Bilingualism: Brain and Cognition, 5(3),175-197. https://doi.org/10.1017/S1366728902003012

Estes, Z., \& Adelman, J.S. (2008). Automatic vigilance for negative words in lexical decision and naming: Comment on Larsen, Mercer and Balota. Emotion, 8(4), 441-444. https://doi.org/10.1037/1528-3542.8.4.441

Faust, M., Ben-Artzi, E., \& Vardi, N. (2012). Semantic processing in native and second language: Evidence from hemispheric differences in fine and coarse semantic coding. Brain and Language, 123, 228-233. https://doi.org/10.1016/j.bandl.2012.09.007

Gollan, T.H., Montoya, R.İ, Cera, C., \& Sandoval, T.C. (2008). More use almost always means smaller frequency effect: Aging, bilingualism and the weaker links hypothesis, Journal of Memory and Language, 58(3), 787-814. https://doi.org/10.1016/j.jml.2007.07.001

Grabitz, C.R., Watkins, K.E., \& Bishop, D.V.M. (2016). Cerebral lateralization of first and second languages in bilinguals assessed by functional transcranial Doppler ultrasound. Welcome to Open Research, 1, 15. https://doi.org/10.12688/wellcomeopenres.9869.1

Göz, İ. (2003). Yazılı Türkçe’nin Kelime Sıklı̆̆ı Sözlüğü. Ankara: Türk Dil Kurumu Yayınları.

Harris, C.L. (2004). Bilingual speakers in the lab: psychophysiological measures of emotional reactivity. Journal of Multilingual and Multicultural Development, 25(2), 223-247. https://doi.org/10.1080/01434630408666530

Hsu, C., Jacobs, A.M., \& Conrad, M. (2015). Can Harry Potter still put a spell on us in a second language ? An fMRI study on reading emotion-laden literature in late bilinguals. Cortex, 63, 282-295. https://doi.org/10.1016/j.cortex.2014.09.002

Jonczyk, R., Boutonnet, B., Kamil Musial, K., Hoemann, K., \& Guillaume Thierry (2016). The bilingual brain turns a blind eye to negative sentences in the second language. Cognitive Affective Behavioral Neuroscience, 16, 527-540. https://doi.org/10.3758/s13415-016-0411-x Kazanas, S. A., \& Altarriba, J. (2016). Emotion word processing: Effects of word type and valence in Spanish-English bilinguals. Journal of Psycholinguistic Research, 45, 395-406. https://doi.org/10.1007/s10936-015-9357-3

Kim, S.H.O., \& Starks, D. (2008). The role of emotions in L1 attrition: The case of Korean-English late bilinguals in New Zealand. International Journal of Bilingualism, 12(4), 303-319. https://doi.org/10.1177/1367006908098573

Kissler, J., Herbert, C., Winkler, I., \& Junghofer, M. (2009). Emotion and attention in visual word processing - an ERP study. Biological Psychology, 80, 75-83. https://doi.org/10.1016/j.biopsycho.2008.03.004

Kissler, J., \& Koessler, S. (2011). Emotionally positive stimuli facilitate lexical decisions - an ERP study. Biological Psychology, $\quad$ 86(3), 254-264. https://doi.org/10.1016/j.biopsycho.2010.12.006

Knickerbocker, H., Johnson, R.L., \& Altarriba, J. (2015). Emotion effects during reading: Influence of an emotion target word on eye movements and processing. Cognition and Emotion, 29(5), 784-806. https://doi.org/10.1080/02699931.2014.938023

Kousta, S.T., Vinson, D.P., \& Vigliocco, G. (2009). Emotion words, regardless of polarity have a processing advantage over neutral words. Cognition, 112(3), 473-481. https://doi.org/10.1016/j.cognition.2009.06.007 
Larsen, R.J., Kimberley, A., Mercer, K.A., \& Balota, D.A. (2006). Lexical characterstics of words used in emotional stroop experiments. Emotion, 6(1), 62-72. https://doi.org/10.1037/1528$\underline{3542.6 .1 .62}$

Lehtonen, M., Hulten, A., Rodrigez-Fornells, A. Cunillera, T., Tuomainen, J., \& Laine, M. (2012). Differences in word recognition between early bilinguals and monolinguals: behavioral and ERP evidence. Neuropsychologia, 50(7), 1362-1371. https://doi.org/10.1016/j.neuropsychologia.2012.02.021

Mergen, F., \& Kuruoglu, G. (2018). A comparison of bilinguals' lexical processing in their two languages. Pamukkale Üniverstesi Sosyal Bilimler Enstitüsü Dergisi, 33, 149-155.

Ong, E., Hussain, S., Chow, Y., \& Thompson, C. (2017). Variations in Bilingual Processing of Positive and Negative Information. In $6^{\text {th }}$ Annual International Conference on Cognitive and Behavioral Psychology (pp. 36-42). https://doi.org/10.5176/2251-1865_CBP17.14

Opitz, B., \& ve Degner, J. (2012). Emotionality is a second language: It's a matter of time. Neuropsychologia, $50(8)$ 1961-1967. https://doi.org/10.1016/j.neuropsychologia.2012.04.021

Palazova, M., Mantwill, K., Sommer, W., \& Schacht, A. (2011). Are emotion effects in single words non-lexical? Evidence from event-related potentials. Neuropsychologia, 49(9), 27662775. https://doi.org/10.1016/j.neuropsychologia.2011.06.005

Paradis, M. (2004). A Neurolinguistic Theory of Bilingualism. Holland: John Benjamins Publishing Company. https://doi.org/10.1075/sibil.18

Pavlenko, A. (2004). "Stop doing that, la komu skalaza!": Language choice and emotions in parentchild communication. Journal of Multilingual and Multicultural Development, 25(2-3), 179-203. https://doi.org/10.1080/01434630408666528

Pavlenko, A. (2012). Affective processing in bilingual speakers: disembodied cognition? International Journal of Psychology, 47(6), 405-428. https://doi.org/10.1080/00207594.2012.743665

Segalowitz, N.,Trofimovich, P., Gatbonton, E., \& Sokolovskaya, A. (2008). Feeling affect in a second language. The role of word recognition automaticity. The Mental Lexicon, 3(1), 4771. https://doi.org/10.1075/ml.3.1.05seg

Toivo, W., \& Scheepers, C. (2019). Pupillary responses to affective words in bilinguals' first versus second language. PlosOne, 14(4), 1-20. https://doi.org/10.1371/journal.pone.0210450

Vinson, D., Ponari, M., \& Vigliocco, G. (2014). How does emotional content affect lexical processing? Cognition and Emotion, 28(4), 737-746. https://doi.org/10.1080/02699931.2013.851068

Winskel, H. (2013). The emotional Stroop task and emotionality rating of negative and neutral words in late Thai-English bilinguals. International Journal of Psychology, 48(6), 10901098. https://doi.org/10.1080/00207594.2013.793800 